\title{
CIÊNCIA E ENSINO DE CIÊNCIAS: IDEIAS E PRÁTICAS DE PROFESSORES DE CIÊNCIAS NO ENSINO MÉDIO EM CABINDA/ANGOLA
}

\author{
SCIENCE AND SCIENCE EDUCATION: IDEAS AND PRACTICES OF SCIENCE \\ TEACHERS IN HIGH SCHOOL IN CABINDA/ANGOLA
}

\author{
Juliana Lando Canga ${ }^{1}$ \\ TerezinhaValim Oliver Gonçalves ${ }^{2}$ \\ Ruth Gabriel Canga Buza ${ }^{3}$
}

\section{RESUMO}

Neste artigo, apresentamos um recorte de uma pesquisa qualitativa, na abordagem narrativa, desenvolvida com professores de Ciências do Ensino Médio da Província de Cabinda, em Angola. A escola em que os doze docentes da pesquisa trabalham, destina-se à preparação de professores, em nível médio, para atuar no ensino fundamental até a $8^{\mathrm{a}}$ série. Em termos objetivos, buscamos refletir e compreender, a partir de registros escritos de professores de ciências dessa instituição de ensino, que ideias constroem acerca de ciência e de ensino de ciências que orientam a sua prática docente, visto que a maioria deles leciona no ensino médio, na área para a qual não foram graduados. São docentes oriundos de áreas afins, como engenharias, enfermagem, bioquímica e outros possuem somente formação em nível médio de escolaridade. Assumimos a pesquisa qualitativa, adotando a abordagem narrativa, na perspectiva (auto) biográfica. Buscamos as informações necessárias para a construção dos dados a partir de questionários respondidos pelos professores. Os resultados apontam para o predomínio da ideia racional de ciência e o ensino por transmissão, embora identifiquem-se indícios de compreensão de ensino como construção, e a relação da ciência com componentes de Ciência, Tecnologia e Sociedade.

PALAVRAS-CHAVE: professores, ensino de Ciências; Ciência-Tecnologia-Sociedade

\section{ABSTRACT}

In this article, we present an outline of a qualitative research approach in narrative, developed with high school science teachers in the province of Cabinda, Angola. The school in which the twelve professors involved it this research work, is intended to prepare teachers in high school, to work in school until the 8th grade. In objective terms, we seek to reflect and understand, from written records of science teachers in this educational institution, which ideas they construct about science and science teaching that guide their teaching practice, since most of them teaches at high school in an area for which they were not graduates. They are teachers coming from related fields such as engineering, nursing, biochemistry and others have only a high school degree. We implemented a qualitative research, adopting a narrative approach, in an (auto) biographical perspective. We seek the information necessary for the

\footnotetext{
${ }^{1}$ Instituto Superior de Serviço Social - Luanda-Luanda - julicanga@yahoo.com

${ }^{2}$ Universidade Federal do Pará - Belém- Pará- tvalim@ufpa.br

${ }^{3}$ Universidade Federal do Pará -Belém-Pará - -.ruthbuza@hotmail.com
} 
construction of the data from questionnaires completed by teachers. The results point to the predominance of the rational idea of science and teaching by transmission, though it was identified evidence of understanding of teaching as construction, and the relationship of science with components of Science, Technology and Society.

Key-words: teachers, science education, Science-Technology-Society

\section{INTRODUÇÃO}

Os questionamentos atuais acerca do "conhecimento", como diz Morin(1994), das "verdades" produzidas e do pensamento complexo que busca ser compreendido, indicam que estamos vivendo uma transição paradigmática de Ciência. Essa transição se estende ao Ensino, especialmente em disciplinas de cunho científico.

Essa transição parece situar-se muito mais no plano das ideias, de tal modo quea trajetória de transitoriedade pode perdurar ainda por muitos e muitos anos, como em outras épocas na história da Ciência, já ocorreu. Na visão de MORIN(1975, apud MARTINAZZO, 2002,p.22), o conhecimento é sempre algo em aberto, em construção e recorrente, sem nunca permitir uma leitura completa que possa esgotar a totalidade do real complexo. Com a quebra do paradigma anterior sobre o conhecimento científico e o seu ensino, vivemos num paradigma emergente que indica o abalo dos pilares que sustentavam este conhecimento durante os três últimos séculos. A ciência, no século XXI,encontra-se em construção de novos caminhos, já não se contentando com relações de causa-efeito, tão fortemente considerada em outros períodos da história da humanidade. Ao deixar de ser compreendida como a única verdade, portanto, absoluta, as incertezas cada vez mais são acentuadas nesse campo do conhecimento, pelo fato de ela não dar conta, neste momento histórico,da complexidade e contingências várias que a sociedade apresenta.

SegundoPrigogine(1996, p.12), noções como a de caos tornaram-se populares e invadem todos os campos da ciência, da cosmologia à economia. Amiséria na África e em outros cantos do mundo, os problemas ambientais, entre outros, são exemplos claros desse caos que invade e ameaça a natureza, nela incluída a sociedade, e o conhecimento científico se apresenta limitado para responder a tais contingências.

Angola, uma nova nação com aproximadamente 10 anos de paz, também tem refletido sobre o assunto, embora numa escala ainda embrionária, relativamente ao que se espera em termos de reflexão e ação nos próximos anos. O país tem um potencial cultural que pode propiciar debates e reflexões sobre o conhecimento científico, não perdendo de vista as outras formas de pensamento, tal como o conhecimento tradicional conhecido como conhecimento popular. Acreditamos num alavancar das ideias perdidas pelo contexto político-histórico em que se viveu durante cinco séculos e trinta décadas, um contexto que desfavoreceu todo um caminhar de construção de conhecimento e de perspectivas de elaboração didáticopedagógicas que permitissem um avanço profundo dessas discussões.

Contudo, recém saída desse contexto político, Angola é hoje um país em franca reconstrução, em vários sentidos. Organiza-se em termos infraestruturais, para proporcionar melhores condições de vida à população e também em termos acadêmicos, centrada na formação de profissionais em nível universitário, dentre os quais destacamos a de professores para a Educação Básica, o que vem sendo acompanhado por meio de pesquisas na área educacional. Nesse contexto de reconstrução social, nosso objetivo nestapesquisa foi investigar ideias de professores que trabalham em uma instituição de ensino médio de 
Cabinda/Angola na área de ciências da natureza, física, química, e biologia sobre ciência e ensino de ciências.

Ao considerarmos um paradigma de transição, é prudente compreender modelos em construção, ou seja, ainda não definidos e totalmente aceitos. Desse modo, entendemos que a ciência e o ensino de ciências estão em processo de construção de pressupostos epistemológicos e metodológicosque deem sustentação aos novos pilares que se tendem a firmar. Ao se denunciar a ruína dos pilares do paradigma anterior, é importante o exercício de procurar compreender como os professores entendem ciência e ensino de ciências no século XXI, em Angola-Cabinda, onde a ciência ainda é considerada a única via para a resolução dos problemas contextuais.

A província de Cabinda, local do estudo,está situada a $800 \mathrm{~km}$ de Luanda, possui uma superfície de $7.300 \mathrm{~km}^{2}$, sendo limitada a Norte e a Nordeste pela República do Congo, a Leste e Sul pela República Democrática do Congo e a Oeste pelo Oceano Atlântico, situado entre os Paralelos $4^{0} 23^{\prime}$ e $5^{0} 46^{\prime}$ de latitude Sul e entre os Meridianos $12^{0}$ e $13^{0} 6^{\prime}$ de longitude Este. Com uma população de, aproximadamente, 500.000 habitantes, tem a língua portuguesa como língua oficial e predominante. Importa salientar que a língua portuguesa é a língua do colonizador. Cabinda concentra grandes potencialidades de recursos naturais, tais como petróleo, e uma floresta rica em biodiversidade, a floresta do Mayombe.

Recorremos à pesquisa qualitativa (GOLDENBERG, 1999, p.52), na abordagem narrativa (CONNELLY \& CLANDININ, 1995), pela qual trabalhamos as informações obtidas, com descrições detalhadas a partir de relatos dos professores investigados.Estabelecemos discussões com a literatura, para sustentação da análise, com o propósito de reconstruir histórias vividas pelos sujeitos de pesquisa por tratar de histórias compartilhadas pelos pesquisadores. Portanto, o campo de pesquisa nos apresenta subsídios para reconstruir as histórias vividas.Compreendemos que essas histórias não são só dos sujeitos da pesquisa, mas também de seus pares e nossas,emboratambém tenhamos vivido experiências diferentes. São nossas histórias, pois, como dizem Connelly \&Clandinin (1995), ao ouvirmos a história do outro, re-significamos nossas próprias histórias. A pesquisa narrativa nos possibilita reviver, reavaliar nossas trajetórias de vida, quer em termos amplos, quer em termos específicos ou restritos. Vivemos por meio de narrativas, afirma Hardy (1998, apud MCEWAN,1995 ). É neste cenário que nos propomos a discutir ideias, buscando caminhos que possibilitem desconstruir e reconstruir algo novo, por meio da subjetividade das histórias e fragmentos de histórias vividas pelos protagonistas desta pesquisa: os professores que ensinam ciências em Cabinda.

Os estudos foram realizados no Instituto Médio de Educação de Cabinda com professores que lecionam Ciências: Química, Física e Biologia no Ensino Médio, com o intuito de buscar entre os doze professores as ideias que defendem, concernentes à ciência e ao ensino de ciências. Sua ideias, ao serem convertidas em vozes, dão possibilidades ao leitor de viver e re-viver histórias por si próprio vividas.

Os doze professores, que trabalham no curso de formação de professores para o ensino fundamental, receberam nomes fictícios de referência: Antoniel, Lauro, Messaque, Davi, Leleco, Suzuki, Pepe, Darlan, Lucha, Paulinho, Leo e Iran. Neste trabalho, contudo, sendo um recorte da pesquisa realizada, trazemos as vozes de Suzuki e Pepe, considerando que foram os sujeitos que mais se manifestaram a respeito da temática focada neste artigo. 
Os sujeitos têm em comum o fato de lecionarem numa área para a qual não foram academicamente preparados, pois vieram de áreas afins,exceto Lucha, que realizou sua formação universitária no exterior, na área de biologia.

Neste artigo, queremos analisar e discutir respostas a questões constantes em um questionário impresso, constituído por perguntas abertas, analisando e levando em consideração o diálogo com a literatura pertinente ao assunto em pauta. Concentramo-nos, portanto, nas respostas escritas dos sujeitos quanto à ciência e ao ensino, considerando aspectos de natureza teórica e prática.

\section{IDEIAS DE CIÊNCIAS E DE ENSINO DE CIÊNCIAS}

Neste estudo, apresentamos, discutimos e analisamos, como dito anteriormente, ideias manifestadas pelos professores investigados acerca de ciência e ensino de ciências. Procuramos situar a análise a partir das vozes dos sujeitos que, embora não tendo formação específica na área de ensino de ciências para lecionar no ensino médio, têm experiência docente, em tempos variáveis de 3 a 30 anos e manifestam ideias a respeito. E, além do mais, são eles que fazem o ensino de Ciências e, portanto, justifica-se estudar o que pensam a respeito do que fazem. Trazemos à tona as vozes dos professores a respeito do que manifestam sobre o assunto em pauta. A seguir, apresentamos as respostas de Suzuki e Pepe.

Suzuki manifesta-se, nos seguintes termos: A ciência é considerada como um conjunto de conhecimentos dos homens sobre o homem, a natureza, a sociedade, o pensamento adquirido pela descoberta das leis objetivas e dos fenômenos; e o ensino de ciência é o ensino desses conhecimentos acerca dos fenomenos da natureza, da sociedade, do homem e as suas relações com o mundo que o rodeia.

Suzuki expressa o entendimento de que a ciência constitui conhecimentos dos homens sobre o homem, incluindo, assim, o conhecimento do homem sobre o humano, como diz Josso (2004). Ao dizer que o ensino de ciências é o ensino desses conhecimentos acerca dos fenômenos da natureza, da sociedade, do homem e das suas relações com o mundo que o rodeia, parece entender, de alguma forma, que as relações homem, natureza e sociedade, neste século, não podem ser dissociadas, e, para uma cabeça bem-feita, conforme nos aponta Morin (2003),o conhecimento é multirrelacional, ligando-se ao todo e não se isolando, como uma ilha. Por isso, ao ensinarmos ciências, na Educação Básica, deve haver essa imbricação, embora saibamos que prevalece, ainda, a compreensão de ensino como transmissão dos conhecimentos construídos pela ciência. Essa compreensão nos leva a crer que o entendimento de ciência, de Suzuki, seja o de verdade absoluta que deve ser transmitida às novas gerações, tal como é apresentada por Santos \& Praia(1992,p.60).

De forma tímida, Suzuki parece, contudo, acenar para a compreensão da interação Ciência-Tecnologia-Sociedade, ao tentar manifestar o seu entendimento sobre ensino, referindo-se ao ensino desses conhecimentos acerca dos fenômenos da natureza, da sociedade, do homem e das suas relações com o mundo que o rodeia. Embora permaneça na relação do ensino desses conhecimentos, o professor parece manifestar ideia das relações que se estabelecem entre os vários participantes do ambiente, visto como ecossistema global. Nesse sentido, as múltiplas relações passam a exigir uma atuação humana que atenda aos deveres e direitos para assumir a cidadania e compreender as relações da ciência e da sociedade com o contexto ambiental, como parte da educação para a cidadania (SILVA \& ZANON, 2000,p.173). 
Entretanto, Suzuki, ao se referir a um episódio da sua prática docente, considerando-o diferenciado, se contradiz ao relatar a prática, sem levar em conta as ideias relacionadas à teoria, quando se manifesta a respeito de ciência e ensino.

É possível que essa situação decorra da dificuldade de colocar em prática um conhecimento intuitivo, posto que suas experiências como aluno e como professor o conduzem a outra prática docente diferente da visão manifestada em seu discurso. O professor, então, relata a aula sobre a lei periódica de Mendeleyev, apresentando o conteúdo conforme consta nos livros de química do Ministério da Educação de Angola, o que transcrevemos a seguir.

Em 1869, o cientista alemão Julius Lother Meyer e o cientísta Russo Dimitri Ivanovich Mendeleyev apresentaram trabalhos muito semelhantes, no que diz respeito às conclusões a que chegaram a cerca da lei periódica dos elementos químicos - Meyer estudou as propriedades físicas e Mendeleyev as propriedades quimicas dos elementos. Na conclusão de seus estudos, Mendeleyev ordenou os 60 elementos na tabela periódica; por sua vez, em 1913, o físico Inglês Henry Moseley (1884-1925) estabeleceu o conceito de número atômico dos elementos quimicos.Entre 1915 e 1925,Moseley descobriu que na Tabela Periódica as propriedades atômicas dependem da carga nuclear.

Suzuki destaca uma prática docente que se apoia na história da Ciência. Faz uma apresentação de conteúdos, contudo, sem a ideia de ciência expressa anteriormente- $O S$ conhecimentos acerca dos fenômenos da natureza, da sociedade, do homem e as suas relações com o mundo que o rodeia. Na prática, esquece de afirmar qual a preponderância desta lei nos dias de hoje, qual é o significado que essa lei tem para a ciência e para o cotidiano, que os elementos ali expostos são representações ou formas didáticas para facilitar o entendimento acadêmico, etc. Suzuki se deteve a discorrer sobre datas e sobre a organização da tabela naquele contexto.

O professor Suzuki esboça ideia de descoberta e poderia ter feito menção ao aperfeiçoamento da tabela periódica ao longo dos tempos. Poderia, até mesmo, ter apresentado o modo de apropriação desse conhecimento por parte dos manipuladores que "descobriram" outros conhecimentos, o que culminou na elaboração de grandes tecnologias equivocadas, como as bombas atômicas que trouxeram danos ao próprio homem, como manifestação exemplar do mau uso da química nas últimas décadas. Poderia ter comentado que, ao invés de trazer relações saudáveis entre fenômenos da natureza, da sociedade e do homem, vários feitos científicos provocam discórdias entre os povos e problemas de saúde ambiental, como aqueles provocados pelo buraco na camada do Ozônio na atmosfera, por exemplo.

Odocente tinha possibilidades de ter relacionado o ensino da tabela periódica com a vida prática, social, tecnológica e cultural dos educandos, como ele afirma em suas ideias sobre a ciência e o ensino de ciências, para que os alunos percebessem a relação direta que há entre o ensino da química e seu cotidiano e, assim, pudessem aproveitar melhor os estudos da disciplina. Isto é importantíssimo: contextualizar os conteúdos e correlacioná-los. O professor deve mostrar habilidade e buscar alternativas para deixar a aula clara, dinâmica, atraente, principalmente num país como Angola, onde os recursos minerais são abundantes e podem ser relacionados com os vários grupos de elementos químicos da Tabela Periódica.

O aluno poderia ser levado não somente a conhecer o conteúdo em termos de Química, mas instigado a pensar e formular uma riqueza de relações que podem ser feitas 
para a construção do conhecimento de forma contextualizada com componentes de Ciência, Tecnologia e Sociedade, como Suzuki acenou de forma teórica já que Cabinda apresenta-se como uma província com grandes potencialidades de recursos naturais como: petróleo,um vasto Oceano Atlântico, e a maior floresta em biodiversidade, a floresta do Mayombe. Nesses moldes, Silva \& Zanon (2000,p.173) afirmam:

Ao se ter o entendimento da ciência como uma construção social e por isso inserida dentro de um contexto social, político, econômico e cultural, torna-se incorreto ensinar ciências de forma descontextualizada, dogmática, distante e alheia às aspirações e necessidades da comunidade, resumida a apresentações de definições científicas.

Contextualizar o ensino de ciências possibilita chamar à responsabilidade o indivíduo diante dos desafios da pós-modernidade e da reconstrução nacional,oferecer condições de exercer a cidadania com plena consciência, com capacidade de contrapor a euforia dos grandes monopólios que visam à exploração desses recursos sem compromissos ambientais, culturais e políticos com o país. Se o entendimento de Ciência como construção social ocorre, a contextualização do ensino se faz necessária, especialmente em um país em reconstrução social como Angola. Nesse sentido, os autores afirmam:

\footnotetext{
Por isso, ensinar ciências na perspectiva da relação Ciência, Tecnologia e Sociedade é uma das formas de criar, através da ciência, consciência civil com responsabilidade social e política e também de proporcionar atitudes e ferramentas intelectuais necessárias para julgar, avaliar no campo do domínio técnico e científico (SILVA \&ZANON, 2000,p.173).
}

De forma teórica, Suzuki parece acenar para essa realidade quando diz a ciência é considerada como um conjunto de conhecimentos dos homens sobre o homem, a natureza, a sociedade, o pensamento adquirido pela descoberta das leis objetivas e dos fenômenos; e o ensino de ciência é o ensino desses conhecimentos acerca dos fenômenos da natureza, da sociedade, do homem e as suas relações com o mundo que o rodeia. Mas, na sua prática docente narrada, a realidade é outra. Essa dicotomia entre o pensar e o agir certamente pode ser explicada, também, pela transitoriedade que, certamente, o professor vive, ao constituir-se professor por processos auto formativos, já que ainda não teve possibilidade de realizar um curso superior de formação de professores.

Desta forma, considerando o contexto de Angola, no pós-guerra civil, em momento de reconstrução nacional, por meio do ensino de ciências, é possívelensinar, levando em conta as aspirações da atualidade, oferecer condições do aluno exercer a cidadania com plena consciência, com capacidade de se contrapor à euforia dos grandes monopólios que visam à exploração dos recursos naturais, sem compromissos ambientais, culturais e políticos com o país, como afirma a reportagem da Revista Exame (DWECK,2006,p.72): Angola agora é um bom negócio, porque o país atrai empresas que lucram com a exploração de recursos naturais. Conforme nos ensina Chassot (2003,p.31),nossa responsabilidade maior, ao ensinar ciências, é procurar que nossos alunos e alunas se transformem, com o ensino que fazemos, em homens e mulheres capazes de questionar, discutir, refletir sobre as necessidades do contexto em que vivem.

\section{IDEIAS DE CIÊNCIAS COMO VERDADE ABSOLUTA}

Pepe, por sua vez, questionado sobre o assunto, afirma: a ciência é um conhecimento racional e certo sobre a natureza da existência das coisas e o ensino de ciências é a 
transmissão desses conhecimentos adquiridos através de investigações metodológicas das leis dos fenômenos naturais.

O professor Pepe, mesmo tendo clareza de que ciência é um conhecimento construído por meio de investigações, manifesta compreendê-la como algo racional e certo, o que parece ter o sentido de inquestionável, de absoluto, de imutável, como compreendiam os filósofos da ciência moderna, o que prevaleceu durante todo século XX (Bacon, com influência dos empiristas ingleses dos séculos XII, XVIII e XIX, entre outros). Por outro lado, a expressão conhecimentos adquiridos pode nos permitir a compreensão de que Pepe entende que os conhecimentos estão prontos na natureza, bastando descobri-los. Essas ideias são corroboradas pela manifestação de que os laboratórios deverão existir para apoiar a teoria, como diz o professor ao se referir às condições necessárias para o ensino.

Essa forma de pensar está baseada na racionalidade técnica (SCHÖN, 1992), fruto da formação escolar, na qual o Positivismo ainda se faz presente em época de transição paradigmática, em que se constrói a pós-modernidade. Ainda nos deparamos com um conceito abstrato de ciência, ahistórico, isento de qualquer subjetividade,privilegiado para os escolhidos, distante do "Eu" como ser humano, sem poder adentrar nele para entender o mundo que o cerca, descontextualizado. Nesse sentido, estabelece-se uma cisão entre pesquisa e prática educacional, reforçando a hierarquização entre o discurso de quem produz e de quem consome o conhecimento cientifico (CHAVES, 2000,p.42).

Ao entender a ciência desta maneira, o docente simplesmente reproduz ou transmite os conhecimentos "descobertos" e acumulados pelos cientistas ao longo da história da humanidade. É a racionalidade técnica implícita na fala de Pepe, quando chama de conhecimento racional aquele relacionado com a ciência, fechado, que norteia o ensino de ciências durante quase cinco séculos em Angola. Sobre esse assunto, Caley $(2005, p .15)$ afirma o seguinte: escusado será que um país vale tanto quanto vale o seu ensino. E Angola parece insistir no modelo herdado pelo colonialismo cuja caducidade é bem evidente. Um modelo desprovido de reflexões, sem um olhar crítico sobre a ciência, é um saber científico adquirido de forma equivocada, sem produzir ganhos para a sociedade, que desconhece o conhecimento endógeno, atrelada às convulsões políticas e ao fenômeno colonial de cinco séculos, não sintonizado, ainda, com o grande projeto que é a finalidade da ciência: o bem estar de homens e mulheres.

Autores como Santos \& Praia (1992,p.60) nos chamam a atenção para a relação que se estabelece entre a compreensão de ciência e de ensino de ciências, quando afirmam:

\footnotetext{
Se o processo de ensino-aprendizagem desenvolvido no meio educacional e a produção da ciência são vistas, por exemplo, como produtos de verdade que deve ser aceita por revelar fenômenos e fatos objetivos da natureza e no contexto social, o ensino tende a tecer tais verdades, torná-las aceitas e repetidas, sem necessidade de uma visão crítica sobre elas.
}

Em um mundo dito globalizado, a velocidade das informações transcende os centros acadêmicos, mas, infelizmente, o ensino de ciências, na maioria das vezes, não acompanha as transformações da atualidade. Nem sempre os assuntos discutidos em aula são apresentados de modo crítico sobre a ciência, buscando valores a eles relacionados, quer do ponto de vista social, quer econômico ou ambiental.

Desse modo, informações subliminares que acompanham propagandas e divulgação de produtos e serviços oferecidos à sociedade manipulam conceitos e continuam perpetuando a superioridade da ciência sobre outros saberes, visando a interesses pessoais ou particulares de determinados setores da sociedade de consumo em um mundo onde o mercado dita as regras do jogo (CANDOTTI,2002 apud VALE 1998). 
Ao mascararmos as possíveis relações da ciência com o cotidiano, a racionalidade técnica da ciência se perpetua no mundo escolar e acadêmico e em todas as partes do conhecimento. Por conta disso, a racionalização da ciência é salutar para os grandes monopólios que manipulam o conhecimento científico, visando ao lucro imediato e rápido, tornando a ciência utilitária para satisfazer os egoísmos e os prazeres de uma minoria dominante.

Pepe considera a ciência como um conhecimento racional e certo sobre a natureza. Essa compreensão o leva, de um modo coerente, como nos mostra Santos \& Praia (1992,p.60), a compreender o ensino de ciências como a transmissão desses conhecimentos adquiridos através de investigação das leis e dos fenômenos naturais.

Morin(1994) afirma que durante três séculos o conhecimento científico não fez mais do que provar suas virtudes de verificação e de descoberta em relação a todas as áreas de conhecimento. É nesta linha que Pepe a chama de certa e racional. Paralelamente a esses acontecimentos, os progressos técnicos, tais como a domesticação da energia nuclear e os princípios da engenharia genética, foram marcos na humanidade em termos de conhecimento científico. Com isso, permitiu elucidar, resolver enigmas e dissipar mistérios, contribuindo com necessidades sociais.

Porém, é essa mesma ciência certa e racional, como diz Pepe, que cada vez mais traz problemas graves que se referem ao conhecimento que produz e à ação que determina a sociedade que transforma. Mesmo com esses problemas, é curioso perceber que os cientistas parecem nem sempre fazer ciência refletindo sobre as consequências do que estão a fazer, usando-a de forma clássica, racionalista e redutora, com possibilidades de impasses extremamente perigosos.

Pensar como Pepe se expressa parece ser algo compreensível no contexto em que ele se insere, vindo de uma ciência experimental técnica, como é a engenharia agronômica, com poucas chances de ter formação continuada visando a sua formação professoral. Esse contexto se agrava por outras lacunas existentes no Ensino Médio de Angola, tais como a falta de currículos adequados e de materiais bibliográficos disponíveis ao professor para uma auto formação mais eficiente, que permita a discussão da ciência em outros moldes. Assim, o conhecimento sobre a ciência, obtido tradicionalmente nos cursos específicos de formação profissional técnica, se perpetua como sendo racional e é compreendida como verdade absoluta.

\section{CONSIDERAÇÕES FINAIS}

Em síntese, foi possível enxergar nas ideias dos sujeitos sobre Ciência e ensino de Ciências as seguintes manifestações: a) Ciência como conjunto de conhecimentos sobre os homens, a sociedade e a natureza; b) Ciência como um conhecimento certo, racional, absoluto e verdadeiro; c) Ciência como detentora da verdade; d) Ciência como área de conhecimento científico; f) Ensino de Ciências como transmissão; g) Indícios do ensino como construção do conhecimento; h) Indícios de compreensão do Ensino de Ciências como relações CTS; i) A importância e a relevância da investigação para se compreender o conhecimento científico.

\section{REFERÊNCIAS}


CHASSOT A. Alfabetização CIENTÍFICA questões e desafios para a educação. Unijuí Rio Grande do Sul 2003.

CALEY, C. Contribuição para o pensamento Histórico e sociológico Angolano (intervenções e reflexões) Nzila, Luanda -2006.

CONNELLY, F. M; CLADININ, D.J. Relatos de Experiência e Investigacion Narrativa. IN: LAROSSA, J. Dejame que te cuete: Ensayos sobre narrativa y educación. Barcelona Laertes, 1995.

CHAVES, S. Por uma epistemologia da formação docente: o que diz a literatura e o que fazem os professores. IN: SCHHNETZLER, R. \& ARAGÃO, R. M. R: UNIMEP/CAPES Campinas, 2000.

DWECK, D. Angola Agora é um Bom Negócio. IN: Revista Exame Edição 877. Ano 40. N¹9 2006.

GOLDENBERG, M. A arte de pesquisar: como fazer pesquisa em ciências sociais. Recorde:Rio de Janeiro 1999

JOSSO, M. C. Experiências de Vida e Formação. Trad. de José C. e Júlia F. São Paulo, 2004.

MORIN, E. Ciência com consciência. Trad. Portuguesa de Maria Gabriela de Bragança e Maria da Graça Pinhão. Portugal: Publicações Europa-America, Lda, 1994.

MORIN, E. A cabeça bem-feita: repensar a reforma, reformar o pensamento. Rio de Janeiro: Bertrand Brasil, 2003.

McEWAN, H. \& EGAN, K. La Narrativa em La Enseñanza, El aprenizaje y La investigación. Argentina: Amorrortur ed,1995.(Coleccion Agenda educativa)

JOSÉ, M. A utopia de Edgar Morim: da complexidade à concidadania planetária. Ijuí: Unijuí,2002.

PRIGOGINE, I. O Fim das Certezas: Tempo, Caos e as Leis da Natureza. UNESP: São Paulo. 1996.

SILVA, R ; ZANON, L. Ensino de ciência e cidadania. IN: SCHHNETZLER, R. P. \& ARAGÃO, R. M. R: UNIMEP/CAPES Campinas, 2000.

SCHÖN, D. La formación de profissionales reflexivos: hacia um nuevo diseño de la enseñanzay el aprendizaje em la profesiones. Paidós: Barcelona, 1992.

SANTOS, E. \& PRAIA, J. Percurso de mudança na didática das ciências. Sua Fundamentação Epistemlógica. Aveiro: Portugal 1992.

VALE, J. Questões atuais no ensino de ciências. IN NARDI, R.(org), escrituras: São Paulo.1998. 